\title{
Challenges of Forensic-Technical Expertise of Documents for Determining the Terms of Their Production
}

\author{
Elena R. Rossinskayaa ${ }^{a}$ Kseniia O. Gorshkovab, \\ Natalia P. Kirillovab, Nikolay G. Stoyko ${ }^{\mathrm{b} *}$, \\ Elizaveta O. Kirillova ${ }^{c}$, Svetlana V. Kochemirovskaia ${ }^{b}$ \\ and Vladimir A. Kochemirovsky ${ }^{\mathrm{b}}$ \\ ${ }^{a}$ Kutafin Moscow State Law University \\ 9 Sadovaya-Kudrinskaya Str., Moscow, 125993, Russia \\ ${ }^{b}$ Saint Petersburg State University \\ 7/9 University Embankment, St. Petersburg, 199034, Russia \\ 'Inter-Regional Economic and Legal Office \\ 1D, 69 Blagodatnaya Str., St. Petersburg, 196105, Russia
}

Received 17.01.2019, received in revised form 18.02.2019, accepted 11.03.2019

The article discusses the problems of forensic-technical expertise by determination of handwritten signatures (records). The main techniques of such examination are described, as well as the problems, which experts face. Here the questions of qualification of experts are raised and recommendations about the choice and appointment of an expert are made. The article provides references to scientific materials in the Russian and foreign scientific sources and also gives examples of the current legislation and jurisprudence of arbitration courts of the Russian Federation.

Keywords: examination of inscriptions, falsification of documents, gas chromatography, the Raman spectroscopy, dating of the documents, unity of measurements, qualification of an expert.

The reported study was funded by Russian Foundation for Basic Research (RFBR) according to the research project No. 18-29-16003\18.

Research area: law.

Citation: Rossinskaya, E.R., Gorshkova, K.O., Kirillova, N.P., Stoyko, N.G., Kirillova, E.O., Kochemirovskaia, S.V., Kochemirovsky, V.A. (2019). Challenges of forensic-technical expertise of documents for determining the terms of their production. J. Sib. Fed. Univ. Humanit. soc. sci., 12(3), 410-437. DOI: 10.17516/1997-1370-0402.

(C) Siberian Federal University. All rights reserved

* Corresponding author E-mail address: nstoiko@mail.ru

ORCID: 0000-0002-9102-634X (Rossinskaya); 0000-0002-6815-8467 (Gorshkova); 0000-0002-2692-4346 (N.P. Kirillova); 0000-0002-4523-7816 (Stoyko); 0000-0002-2963-1256 (E.O. Kirillova); 0000-0001-7592-3860 (Kochemirovskaia); 0000-0002-0352-3793 (Kochemirovsky)

This work is licensed under a Creative Commons Attribution-NonCommercial 4.0 International License (CC BY-NC 4.0). 


\section{Introduction}

On one hand, the forensic-technical examination of documents, examination of handwritten inscriptions and stamps application are one of the most demanded types of expert examinations of documents in criminal, civil, adjudicatory and administrative processes. On the other hand these are the most problematic types of forensic examination.

Falsification of documents can be used in different types of crime and also a method of false suggestion for arbitration and regular courts. That is why this expertise is demanded all over the world.

When appointing the examination of the documents' particulars, a judicial or investigative authority wants to get reliable information about actual period when the handwritten text (signatures, notes) was written in the document in gel, ball-point or fountain pen and also by stamps; to identify falsification of documents of different types such as text reprint, sheets' replacement, copying of prints and falsification of signatures, artificial ageing (excandescence, uviolizing, etc.). It is expected that the examination will allow to establish, for example, the fact that the document has been produced recently despite long-term date on it, it will allow to discover true order of particulars' application on the document that is to establish, for instance, that a new text has been printed recently on a clear sheet with old remaining signature and also to establish signs of editing or sheet replacement if the document consists of several sheets.

In practice in many cases an expert cannot answer all the questions that they are expected to answer accurately and comprehensively. The reason is a number of technical and legal problems that need to be described, systematised and solved.

Scientists in many countries actively search for technologies and make attempts to develop methods that are necessary for making legal expertise of this kind. First of all, it is a question of the ability to establish the actual term when handwritten notes and stamps were made in documents. Now the most widespread method of such analysis is chromatographic method based of measuring of dynamic of vaporation of fugative (high-boiling) components of letter materials. Attempts of researchers to bring this method to the level of metrological requirements demanded by the Federal Law No. 102-FZ dated June 26, 2008 "On the uniformity of measurements" from the methods in the government control sphere fail because like any physical-chemical method chromatography has limits of application defined by nature that are hard to overcome. 
That is why in legal expertology of many countries technologies based on other methods of documents' expertise have been actively developing and application of those will allow to remove or expand limits of chromatographic method.

Let us outline research works connected with the application of such methods as:

- high efficiency liquid chromatography (Samanidou, Nikolaidou, Papadoyannis, 2004; Kher et al., 2006);

- capillary electrophoresis (Cruces-Blanco, Gámiz-Gracia, García-Campaña, 2007);

- infrared spectroscopy (Kher et al., 2006; Causin et al., 2008; Dirwono et al., 2010; Silva et al., 2013);

- Raman spectroscopy (Mazzella, Buzzini, 2005; Lombardi et al., 2006, Chaplin, Clark, 2006; Kalantzis, 2008; Geiman, Leona, Lombardi, 2009; Reisner, Cao, Pandya, 2011; Gorshkova et al., 2016; Grechukha et al., 2017).

Legal problems in examination of inscriptions are limitations of standard regulation of getting and using the samples for comparative expert research. Their availability and reliability influence relevancy of expert conclusions and finally, judicial appraisal of expert conclusion. According to p. 9 of the Federal Law No.73-FZ "About state forensic-expert activity in the Russian Federation" dated May 31 $1^{\text {st }}, 2001$ samples for comparative research are independent type of objects used during expertise and their selection depends on the type of expertise and nature of questions. As it is pointed in literature, samples for diagnostic and identification research should be of proper quality, in necessary amount and of reliable origin (Rossinskaya et al., 2016: 93-95). Samples for comparative research are of proper quality when they demonstrate characteristics of the object they were taken from necessary for expert research purposes; amount of samples must be enough to make conclusions if they are necessary or accidental and how they vary. Conditions of getting samples for comparative research must correspond to conditions of appearance of object under study (Rossinskaya, 2018: 37).

In some types of forensic examination, samples for comparative analysis are included in the subsystems of criminalistics registering in state expert-criminalistic agencies of the Ministry of Internal Affairs of Russia. Legal basis of criminalistic registration are paragraphs 12, 1, 2, 33, 13 of the Federal Law No. 3-FZ “On police” dated February $7^{\text {th }}, 2011$; paragraphs 6,10 of the Federal Law No. 144-FZ “On operational and investigative activities" dated August $12^{\text {th }}, 1995$. Procedure of gathering of accountable materials is subject to bylaws, i.e. orders and instructions of the Ministry of Internal Affairs of Russia. 
Samples for comparative analysis for some types of forensic-technical expertise of documents are carried out on federal and regional levels as natural collections and automatised informational-searching systems (AISS), for example, "Ottisk", "Abris", "Deviza-M" and "Znak" AISS are used for expertise of bogus current money and bond-like papers and also falsified documents made by polygraphic method (Rossinskaya et al., 2016: 338). Authenticity of banknotes, universal source of origin of bogus current money and bond-like papers, treasury notes and foreign currency is determined by the method of making, composition and structure of materials. Card system updating is caused by current money and bond-like papers that come after expert examination. "Script" AISS (Cherenkov, 1992: 3-15) allows registering of faked medical prescriptions for drugs and potent medical substances and also samples of handwriting of people who faked them, which makes it possible to determine authors of handwritten texts, the fact of faking of a few inscriptions by one person and also to identify which technical means were used. Nevertheless, these registering methods that have high level of computer equipment do not cover all types of comparative samples that are necessary in forensic-technical expertise of documents.

The so called reference information collections (RIC) that are natural collections of objects and descriptions of objects including documents in state forensic-expert agencies, which are formed and registered along with it. They are built in relation to specific types of expertise, objects or methods of expert examination. Most of them are based on computer environment and systems and are AISS.

In forensic-expert agencies of the Ministry of Internal Affairs, RICs are included in information-supportive registrations that in accordance with standard regulations of the MIA of Russia are a part of the system of criminalistic registration. In forensicexpert agencies of the Ministry of Justice they are registered initiatively. The problem is disunity of RICs because they are often registered separately in departments taking forensic-expert activity. RICs are badly regulated and often do not contain enough information about modern objects and methods of forensic-technical expertise of documents.

Russian laws and regulations do not standardise in details the order of organisation of RICs that is why we have a question about legitimacy of using those when performing examination. For updating such registrations, a forensic-expert agency after finishing record production can solicit court, investigative agency, investigating officer, examining official for getting objects that are physical evidence for using them in expert, scientific and learning and teaching activities. 
The order of getting samples for comparative analysis is different in different forms of law procedures. Herewith expert practice indicates that in many cases samples cannot be presented by an investigating officer for comparative analysis because they failed to get them. In such cases some experts in their job use samples from their own database (collection) that they have been gathering on their own for a long period of time. Legitimacy of such information is often evidence-free and later leads to fatal doubts in evidentiary value of examination.

It is very important for forensic-technical expertise of documents where modern instruments of analysis are used more and more often. It is obvious that we have urgent need to renew, supplement and optimise informational resources that we have in this field.

For long time it was explained by natural restrictions of informational communication between different experts and expert agencies, as well as confidential and safety considerations. In the context of modern level of development of digital and IT-technologies such situation becomes an anachronism especially taking into account the fact that many methods of analysis are based on modern software that makes it possible to keep and process the results of analysis and exchange information about the results with unlimited amount of users in expert community thus eliminating local informational restrictions that many experts face.

This work is dedicated to consideration of listed problems and search of ways to solve them.

\section{Summary of technical problems of inscription's examination}

Currently, the examination of the samples of hand-written documents in ink, balltype and gel inks and also seal impressions as it was mentioned above both in Russia and abroad is mainly based on gas chromatographic analysis (GS) of the constant content of volatile components in written compositions. Almost full evaporation of volatile components of letter materials usually happens in the period from a few weeks to 1.5-2 years (Gaudreau, Brazeau, 2002; Technical expertise of documents, 2004; Lociciro et al., 2004; Bügler, Buchner, Dallmayer, 2005; Weyermann et al., 2007; Bügler, Buchner, Dallmayer, 2008; Borisova, Trosman, Chertkova, 2008; Sitnikov, Venevtcev, 2009; Tuhkanen, Maslennikov, Tovkach, 2011). It is temporary saturation point of chromatographic methods. Herewith total duration of the examination can take from 1.5 to 6 months.

Therefore, if the "age" of particulars of a document is more than 1.5 years then using the gas chromatography method in $90 \%$ of cases causes the answer "is not possible" 
(INP). Herewith, it is necessary to repeat that all methods in research of antiquity that state forensic-expert agencies use today do not have state certification of the Forensic Examination Technical Standardisation Committee No. 134, certifying the state agency of the Federal Agency of Technical Regulation and Metrology (Rosstandard), which has the functions of national, interstate and international standardisation in the field of expert activity in accordance with the order of this agency done for the purpose of implementation of the Federal Law No. 184-FZ "On Technical Regulation" dated December $27^{\text {th }}, 2002$ and also enhancing the effectiveness standardisation in the field of forensic expertise at the national and international levels.

At the same time, any forensic-expert conclusion in Russia in this field is done by expert in accordance with their personal choice based on special knowledge, presence or absence of collections of samples for comparison or in accordance with recommendations of authorities or available technical opportunities. It is neither good nor bad, it is just a fact that the enforcer of law has to take into consideration when deciding on the appointment and performance of inscription's examination.

Moreover, the GS method implies implementation of a few press-cuttings from line marks of particulars to be analysed $2 \times 10 \mathrm{~mm}$ in size. It causes breakdown in the integrity of documents and a change in their original appearance. If signature under examination is very small and most of it is "covered" by a stamp or other details the rest "clear" length of line mark of the detail may be not enough for even primary expertise using the GS method not speaking about additional or repeated examination. In this case getting the INP conclusion from an expert is explained because materials given for expertise are not sufficient for examination. Speaking about examination of inscriptions, lack of materials and improper materials provided for examination, as a rule result in the impossibility to use only the GS method.

Thus, using chromatography in examination of inscriptions is limited due to the reasons listed above. However, these limitations are known and clear, that is why this method allows to "cut off" "fresh" inscriptions (signs) on documents from the beginning.

Meanwhile in the forensic practice we always need to establish limitation of much older documents that 1.5-2 years, to perform repeated and additional examinations within reasonable timeframes of forensic examination. This task stimulates a lot of scientific research in order to solve the problem of establishing the age of handwritten particulars of documents by methods different from the GS methods.

Nevertheless, here researchers also face technical problems that still do not allow to find decisive substitution for gas chromatography, while due to some limitations it is 
not always possible to get accurate results on the basis of which one can make precise conclusion about timeframes of when an inscription was put on a document.

These problems are briefly illustrated in Table 1.

Raman spectroscopy method should be also outlined (Gorshkova et al., 2016; Grechukha et al., 2017).

It should be noted that the analysis methods listed above in most cases allow to solve only identifying tasks. A method of determining the period when inscriptions were made on documents, main aspects of which are given in key European publications

Table 1. Limitations of applicability of analysis methods most frequently applied in forensic expertise of documents

\begin{tabular}{|c|c|}
\hline Method & Main limitations of applying the method \\
\hline $\begin{array}{l}\text { Thin-layer chromatography } \\
\text { (TLC) }\end{array}$ & $\begin{array}{l}\text { Destructive nature; } \\
\text { Not suitable for examination of letter materials that contain paints } \\
\text { insoluble in organic mediums (Zlotnick, Smith, 1999); } \\
\text { Gives only qualitative assessment (Zlotnick, Smith, 1999); } \\
\text { Impossible to separate inks that have the same formula (Cruces- } \\
\text { Blanco, Gámiz-Gracia, García-Campaña, 2007); } \\
\text { Inaccuracy is caused by the procedure of sample preparation that } \\
\text { includes multistage extraction; } \\
\text { Proper differentiation is possible only in 40-45\% }\end{array}$ \\
\hline $\begin{array}{l}\text { High-performance liquid } \\
\text { chromatography (HPLC) }\end{array}$ & $\begin{array}{l}\text { Destructive nature (Cruces-Blanco, Gámiz-Gracia, García-Campaña, } \\
\text { 2007); } \\
\text { Lack of sensitivity, samples of bigger size are needed for simple } \\
\text { analysis (line marks with length more than } 1 \mathrm{~cm} \text { ) (Tebbet et al., 1992); } \\
\text { Expensive equipment (Cruces-Blanco, Gámiz-Gracia, García- } \\
\text { Campaña, 2007; Zlotnick, Smith, 1999); } \\
\text { Labour-consuming preparation of samples (Kher, 2006) that causes } \\
\text { impossibility of express-analysis }\end{array}$ \\
\hline Capillary electrophoresis & $\begin{array}{l}\text { Destructive nature; } \\
\text { Labour-consuming preparation of trials (Shevchenko, Temerdashev, } \\
\text { Kiseleva, 2012). Identification of components by spectrum } \\
\text { characteristics is hard because of limited volume of added trials, } \\
\text { including of preconcentration stage is required; } \\
\text { Low sensitivity trials (Shevchenko, Temerdashev, Kiseleva, 2012); } \\
\text { Hard to identify components trials (Shevchenko, Temerdashev, } \\
\text { Kiseleva, 2012); Because of low signal-noise correlations it is very } \\
\text { hard to determine many minor components with high degree of } \\
\text { certainty }\end{array}$ \\
\hline $\begin{array}{l}\text { Attenuated total reflection } \\
\text { Fourier-Transform Infrared } \\
\text { Spectroscopy (ATR FTIR) }\end{array}$ & $\begin{array}{l}\text { Signal from paper can be higher that signal from written composition; } \\
\text { As any IF spectroscopy it has "fingerprint" as a signal: many } \\
\text { peaks from different components that do not fit each other. Written } \\
\text { composition must be separated before to be identified and that is not } \\
\text { always possible (Dirwono et al., 2010) }\end{array}$ \\
\hline
\end{tabular}


and have been presented at international conferences, was developed on the basis of Raman spectroscopy (Gorshkova et al., 2016; Grechukha et al., 2017; Kochemirovskiy et al., 2015).

The method is not based on the content of medium analysis but it is based on analysis of spectrum characteristics of the main types of inks. Ink type is very important particularly for determining the order of applying particulars on a document. It is not a secret that it is possible to print new text on blank sheet of paper with old reserved signature. Raman spectroscopy examination can establish this fact even if the printed text does not meet the handwritten one.

On one hand, the Raman spectroscopy method does not have many disadvantages and allows to avoid problems of other methods listed in Table 1.

The main advantage of the Raman spectroscopy method in comparison with chromatographic methods of analysis is not destroying, non-invasive nature of impact on the sample, which allows to have repeated analysis if necessary. Samples do not need preconditioning. Raman spectroscopy is a fast and effective method for unmistakable identification of both organic and nonorganic materials meaning that this method has high chemical selectivity. Raman spectroscopy allows to use small parts of the sample $\left(<1 \mathrm{mkm}^{2}\right)$ in analysis with high spatial $(\leq 1 \mathrm{mkm})$ and spectral resolution $\left(<1 \mathrm{~cm}^{-1}\right)$. The "depth" of spectroscopic analysis reaches 10 years unlike 1.5-2 years in chromatography.

Quite little radiative power (in average about $4 \mathrm{~mW}$ ) is enough to get Raman spectrum that minimizes the potential risk of laser-induced degradation.

On the other hand, the disadvantage of applying of Raman spectroscopy is fluorescence signal that sometimes interferes with getting proper spectrum. Fluorescence can appear because of radiation of the sample, particularly if the sample contains some organic compounds. This phenomenon is caused by absorption of the sample's radiation by molecules and creating its own broadband radiation that can be much more intensive than the Raman one. It is possible to avoid problems with fluorescence using radiation with larger wavelength.

Nevertheless, we need to remember that the intensity of Raman spectroscopy is proportional to the fourth degree of the intensity of driving frequency, in other words the control of long-wave radiation gives a much less intense combination signal than the control of short-wave radiation (Chaplin, Clark, 2006; Geiman, Leona, Lombardi, 2009).

On the basis of brief analysis of modern condition of research in this field we can make an important statement: any attempts to find a universal remedy for determining 
the date of putting handwritten inscriptions and stamps on a document in the form of one unique physical-chemical method that will give an answer to all questions will fail. A complex approach suggested below should be the main direction of solving technical problems in this field.

For the first time in the forensic-technical examination practice a new approach in expert examination is suggested and it includes combining traditional gas chromatographic and spectrophotometric analysis with the Raman spectroscopy method for creating proper technology that meets the requirements of modern investigative and forensic practice. Expert examination is based on examining the dynamic of spectral characteristics of colouring materials that are a part of the basis for written and painted compositions. The suggested approach makes it possible to recognise objects up to 10 years old, shortens the terms of expert examination to 1.5-2 months, partially saves an object for repeated examinations.

Later, with the invention of new methods of analysis, their possibilities should be included in the standard procedure. With the help of such a "lie detector" for a document it will be finally possible to create an instrumental-methodical complex which will allow to determine the date of inscriptions with high reliability, accuracy and almost without mistakes.

It should be outlined that only using a few different methods of physical-chemical analysis simultaneously will allow to get a potentially unmistakable result in some cases. Therefore, when the expertise is done it is desirable not to use chromatography as the only expert's instrument of analysis but it has to be used as a necessary stage of examination. Thus, the choice of suitable method of expertise is a key factor that allows to get the expert's conclusion that will be accepted by court and will form no justification to appoint repeated expertise.

Examples of this approach can be opinions in arbitration cases where the methods of the Ministry of Justice (Borisova, Trosman, Chertkova, 2008; Tuhkanen, Maslennikov, Tovkach, 2011) and Raman spectroscopy method (Gorshkova, 2016; Grechukha, 2017) were applied at the same time.

Thus, in one of the cases the plaintiff accused the defendant of faking the plaintiff's application for gas supply that the plaintiff did not apply for and which caused significant damage to the plaintiff because in fact gas was not received. The defendant insisted on the authenticity of the plaintiff's application. In connection with the fact that the court provided experts with samples of comparison materials of letters which were examined with GC and Raman spectroscopy methods with the view to establish their 
spectral and chromatographic correspondence to the given samples. As a result experts managed to find signs of falsification in parts of the documents and to identify part of the documents as original and thus to establish that each party had exaggerated truthfulness of their opinions and the truth in this case did not correspond to none of the parties.

Moreover, there is a representative case where the plaintiff and the defendant delivered to court two copies of the minutes of disagreements on a contract. According to the plaintiff's copy the guaranteed use period of smoke flue was 25 years while in the defendant's copy the guaranteed use period was only 5 years. Primary expertise with gas chromatography method did not give any results. Therefore, a repeated examination with Raman spectroscopy method was appointed.

Samples for comparison were also given to the expert. If we sum the results of two methods experts reliably ascertained that handwritten note "5 (five) years" on the defendant's minutes of disagreements were made in the period 2013-2014. At the same time the handwritten inscription "25 (twenty five) years" on the plaintiff's minutes of disagreements corresponded to the time period June 2006 - February 2007. Herewith, the date range 2013-2014 at the moment of research was in the range of chromatographic method but 2006-2007 was determined with the help of Raman spectroscopy. It played an important role that the choice of samples for comparison for chromatographic method is almost an impossible procedure because in written compositions there are more than ten volatile components in different combinations. But there are only 3 types of inks with some exceptions that are objects for research in case of the Raman spectroscopy method and very often only one of them is a part of letter material. It makes the problem of choosing samples for comparative research much simpler.

In the present case, the conclusion of the expert was taken as the basis for decision of the arbitration court of the Penza region from May $24^{\text {th }}, 2016$ with regard to the case A49-12796/2014. Subsequent authorities left that decision unchanged.

Technology that is described above was practically used in more than 60 expert conclusions that were given to both arbitration courts and courts of general jurisdiction. Approximately half of examinations that were appointed were repeated because primary expertise was not able to give answers to the questions set by the court.

Creating an instrumental-methodical complex is impossible without digitalisation of the process in the form of centralised base of spectral data of examined samples. As we have already said above digital databases are widely used for analysis of a variety of 
documents (for example, paper money, which includes foreign currency, documents of state-level treatment and some others) because they have many advantages comparing with natural collections. In particular, digital bases contain almost unlimited scope of information that can be accumulated and given to an expert, provide with an opportunity to save data about present condition of an object under study over any time period. Herewith, expenses for database's maintenance are minimal. Using such databases reduces subjective factor in comparative analysis, there are unlimited possibilities for access to the information and data. However, due to specific character of objects these databases are available only for forensic experts of some specific state forensic-expert agencies. First of all, it is connected with the defence of the National Security Information and personal data of citizens.

For creating a digital database for forensic-technical examination connected with establishing time periods and time limits of documents' implementation such limits do not exist. An organisation that created it will have an opportunity to become not just a national but also an international centre of informational-methodical information in this field. Both state and non-state expert agencies in Russia and abroad will be able to get an access to it, on a commercial basis as well. However, this requires drafting of recommendations for development of regulatory control of the organisation and using natural collections, storage and use of digital databases.

The new approach has been successfully implemented because its authors have a unique instrumental-methodical database of the scientific park of Saint Petersburg State University. Research in the field of documents' dating are based on possibilities of the Centre for Optical and Laser Materials Research. The essence of activity of the Centre for Optical and Laser Materials Research is doing a lot of experimental research both with the purpose of determining the composition, optical and physical-chemical characteristics of different elements and materials and with the purpose of research of a wide range of physical phenomena when interreacting with elements.

Complexity and flexibility of equipment, resource centre's team and also cross-disciplinary character of issues to solve allow to implement in practice high-efficiency combination of scientific-research and educational activity using modern optical, laser and accompanying world-class instruments. The Centre for Optical and Laser Materials Research has a unique instrument set: express Raman spectrometer SENTERRA (Bruker). It can make measurements of liquids and solid samples: glassy, crystal, organic and non-organic substances in the form of powder, thin layers. It can work with trace amounts of substances. This complex 
has the Olimpus system of optical visualisation of samples. The spectrometer has three lasers with wavelengths 488, 532, $785 \mathrm{~nm}$ and fibre-optic detector for Raman spectra registrations: $80-4500 \mathrm{~cm}^{-1}$. Wavelengths of driving lasers (maximum power is written in brackets): $532 \mathrm{~nm}(20 \mathrm{~mW}), 785 \mathrm{~nm}(100 \mathrm{~mW}), 488 \mathrm{~nm}(20 \mathrm{~mW})$. The detector: high-sensitive $\mathrm{CCD}$ detector with Peltier cooling to $-70^{\circ} \mathrm{C}$. Two diffraction grids -400 marks $/ \mathrm{mm}$ and 1200 marks $/ \mathrm{mm}$.

Working with such complex and interpretation of results of its measurements demands high scientific and professional qualification of an expert. The above is also true of qualified work in the field of chromatography that is why when choosing an expert it is necessary to pay attention to their industry-specific education in the expert field and pay attention to research chops in the database of RSCI of Department of Science and Education of the Russian Federation (http://elibrary.ru/authors.asp). The higher these metrics are the more qualified the expert is. However, this significant metric often escapes the attention of courts when considering the issue of qualification of an expert.

Such complex research based on the requirements of the Federal Law No.73FZ on the newest accomplishments of science and technology can be done only by high-qualified specialists in the field of forensic expertise of substances, materials and products who are masters of methods of analytical chemistry and physicalchemical methods of analysis. Unfortunately, officially this type of forensic-technical examination is considered as criminalistic research of documents and it is done by experts-criminalists who attended short-term courses of additional education, which do not provide necessary knowledge.

Expert practice says that some research is done not only by experts-criminalists who at least have education in specialty "forensic examination", "criminalistic expertise" specialisation that study forensic-technical examination for a year but they are not masters enough in methods of research of materials of documents, but also by specialists who have basic veterinary education, engineers-mechanics.

Without denying their responsible approach to expert research, nevertheless we should pay attention to circumstances that possibilities of research plan construction and correct interpretation of results have some natural limits. In some cases, expert organisations suggest their own original methods that are not published anywhere and based on analysis methods: nuclear magnetic resonance, spectrophotometry (method of colour determination). Authors account scientific accuracy of these methods for getting a patent of the Russian Federation for invention. 
When estimating experts' conclusions based in these methods, the law-enforcer should take into account that a patent just confirms intellectual property right of an author and owner for inventions and in no case means that it has scientific validation. Rospatent only observes that the author does not copy already-known patents. In our opinion methods used by an expert except patent should have confirmation in the form of departmental recommendation (Ministry of Justice or Ministry of Internal Affairs of Russia), get approval and be probated by the Forensic Examination Technical Committee No. 134 of Rosstandard.

Some organisations advertise their chromatographic expertise using the legend about closeness to "Professor Aginsky", a Russian scientist who left for the USA long time ago and whose method of establishing handwritten documents dating in the 90s was really an alternative for the method of the Ministry of Justice (Aginsky, 1993; Aginsky, 1996).

Chromatgraphic methods of Aginsky continue developing in Europe and USA but organisations who advertise these methods in Russia do not have real material and scientific base for performing examinations using these methods and they misinform courts saying that a chaotic set of actions they use is the method of Aginsky.

Information above confirms that one of the key moments in the choice of an expert organisation is the instruments for the expertise that organisation has. Terms of execution of an examination are also significant.

The main problem of non-state organisations is that almost none of them has real instrumental and scientific-methodical base for appropriate performance of even the methods of the Ministry of Justice of Russia (Borisova, Trosman, Chertkova, 2008; Tuhkanen, Maslennikov, Tovkach, 2011), not speaking about other modern methods.

Overwhelming majority of non-state expert organisations have in the best case only a chromatograph and sometimes they do not have even this one. That is why many stages of necessary research are missed by such organisations and they rightly suppose that the court will not notice it. However, the result that they get is not very much different from random numbers generator and does not give any information about the subject of analysis.

That is why when the law-enforcer chooses an expert organisation even for the performance of just one chromatographic method they should take into consideration if it has specific equipment: an optical microscope, a chromatograph with a metering unit for solid trials, a spectrophotometer. Specific attention should be paid to availability of a metering unit for solid trials and a spectrophotometer. When this equipment is 
absent experts start to "invent" pseudoscientific methods, analyse extracts of the most unimaginable compositions, get unpredictable results and misrepresent it as results of analysis.

2. Problems of legislative regulation of expert activity, quality of expert methods and expert qualification

The first legal problem that an expert who starts analysis of the particulars of a controversial document faces is receiving and legitimation of available samples for comparison.

Depending on time and conditions of their appearance, samples for comparative analysis are usually divided into three groups: free, experimental and conditionallyfree. Free samples are samples that appeared before the beginning of proceedings on the case and are not connected with it. It can be materials of writing, form's content, applications, signatures on different documents and other texts that are made with one's own hand. These samples can be found by participants of the process at the place of residence, work, study, in banks, tax agencies and other state agencies, etc. When they are found, the court must establish if they were written by a specific person. Conditionally-free samples are samples that were created after initiation of proceedings but not in connection with preparation of materials for expertise and for the purposes of comparative analysis. For example, signatures that were made in investigation and forensic protocols, objective evidence, signatures in other official documents can be used as such samples. Experimental samples are objects that were purposefully obtained by an expert, investigator or court for the purposes of comparative analysis (Rossinskaya et al., 2016; Rossinskaya, 2018).

Samples for comparative analysis can be presented by parties according to the scheduled procedure of reclamation and presenting evidence to the court.

Forensic practice accepts using such samples if the court has no doubts about the conditions in which they were obtained and kept. It appears that from the judicial point of view creating such collections and using them in the process of expert research is a part of an expert method. Courts must evaluate propriety and accuracy of expert's conclusion considering this part of the method applied as well.

We should take into account that in forensicpractice there is often situation when examples of comparison are reasonably absent or one of the parties is not interested in providing them. In this case, an expert is forced to use data that natural collection of expert agency has. 
Many monographs are dedicated to the development of scientific basics for creating and using natural collections for criminalistic purposes and their digitalisation. They were mentioned in expertology educational books (Pakhomov, 1998; Rossinskaya et al., 2016; Shvedova, 1999; Beeva, 2003; Sretensev, 2009).

Using collections of state forensic-expert agencies and databases, first of all, of the Ministry of Internal Affairs of Russia, is regulated by departmental standard regulation. These collections and databases are meant for criminalistic purposes and cannot be given to non-state forensic-expert organisations like many methods of expert research in general.

It is explained by several factors.

First of all, the legal status of non-state forensic-expert organisations in the present time is not determined at the legislative level. In the Federal Law No. 73-FZ there is only one paragraph 41 that extends some regulatory requirements on non-state experts. However, nothing is said about non-state forensic-expert organisations (Rossinskaya, 2002: 361-368). It is supposed that the legal status of non-state forensic-expert agencies and their organisation will be regulated by the Federal Law "About forensic-expert activity in the Russian Federation" that has been discussed in the State Duma of the Federal Assembly of the Russian Federation.

Secondly, even the official federal law determines only most common regulations of legal and organisational support of non-state forensic-expert agency's activity (Rossinskaya, Galyashina, 2009). Implementation of the rule of law will demand more detailed workout of problems and generalisation of forensic-expert practice on the basis of forensic expertology using scientific research. Development of individual theories about legal and organisational support of non-state forensic-expert organisations is needed.

It is obvious that by virtue of its specificity non-state forensic-expert agencies cannot perform some types of forensic examination of documents and have access to some computer databases by virtue of special aspects of provision of objects' safety and limited-access to them. From our point of view, it is necessary to study and regulate the problem of accessibility of databases and forensic-expert methods that are being invented in state forensic-expert agencies for non-state ones. Special legal regulations must be invented for this purpose because fully opened access to databases and methods and what is critically important to boundary conditions of their use can be used in illegal activities. For instance, in our practice we had a case when description of our method of research of copper conductors stained with burning-off (Mitrichev et 
al., 1992) in a monograph of one famous scientist (Smelkov, 2009: 256-260) was used in imitating a fire situation because of short circuit in order to hide the fact of burning.

It is necessary to create universal regulatory, scientifically based and organisationally supported system of databases, completing and using them in state and non-state expert agencies.

Subparagraph 4 of Paragraph 202 of the Criminal Procedure Code of the Russian Federation gives an expert the right to get samples for comparative analysis if this action is a part of forensic expertise. Other procedural codes contain similar regulations. Therefore, we can make a conclusion that during forensic examination an expert can get samples (which also includes creating a collection of samples) for comparative analysis.

In some studies of last years, there were suggested recommendations about creation and use of informational funds that contain information about characteristics of modern materials of letters. There was a determined structure of such funds that consists of collections of samples of letter materials (in natural and describing form) and automatised informational-helping list of objects of criminalistic research of this category (Barinova, 2015).

It should be noted that in the field of chromatographic analysis real creation of such collection is quite difficult because samples change their characteristics very fast during storage. Except that the market of written compositions is increasingly renewed and original samples lose their actuality in short-time periods. Storing them in actual condition is a hard procedure that demands on one side high accuracy and on the other hand responsiveness in keeping track of changes in written compositions market.

Digital database of spectral data is a different thing. Every spectrum that was got on modern spectrometer is a digital file that registries condition of the sample under research at the moment of analysis. In such case spectrum reflects all smallest individual special aspects of the sample that had been recorded during the process of measurements for long period of time. When all spectrums of all samples that were under research are saved we can make automatic computer search of all full or nearest spectral analogues getting at the same time information about quality and quantity composition, time, place and conditions of making the inscription. As distinguished from solvents the amount of colourants used in written compositions is very limited. Only three main types (Gorshkova et al., 2016; Grechukha et al., 2017) has been used for approximately a century and in present time nothing designates any "revolution" in this field. Circumstances listed above make the procedure of updating and keeping base of spectral data in actual condition significantly simpler. 
Proper law regulations of the procedure of data exchange from present collections for creating a universal base of informational-helping lists for all expert agencies can help experts greatly. Possibility of creating and updating informational bases of forensic-technical examination is straightly connected with creating new physicalchemical methods of letter materials' analysis and analysis of paper media based on using modern digital technologies. Considering complex character of forensic-technical examination, hardware and software systems that are being created must be integrative and provide informational support of examination of both particulars and documents.

Suggested spectral methods of documents' examination allow an expert agency to effectively use modern digital technologies. In particular, they provide an opportunity to create universal digital databases of spectrums of different objects of forensictechnical examination that can be later used as standard or informational data in other objects' analysis.

Digital databases have significant advantages comparing with natural expert collections that are created in different state expert agencies. Their advantage is that digital database allows to register characteristics of an object under study during the whole period of its existence, not only at the moment of examination which is of significant importance when an expert is determining time frames of any events or processes which took place. It can be universal and centralised for all expert agencies of the Russian Federation and it will contribute to the integration of Russian experts into the international expert society.

Disadvantages of legal regulation of the process of creation, keeping and using natural collections can cause reasonable doubts in expert conclusions' accuracy. Creating and using new type of expert databases that are based on digital technologies demands especially proper legal regulation not only for state but also for non-state expert agencies.

One more problem of legal regulation of expert activity in this field is impossibility to apply in expert practice some regulations of the Federal Law No.102-FZ of the Russian Federation “On providing measurements' unity” dated June $26^{\text {th }}, 2008$. As we have already mentioned above the specific feature of the forensic-technical examination is the fact that an expert gets significant part of expert data in consequence of straight or sideway measurements with the help of relevant measuring facilities (instruments, equipment).

In accordance with Paragraph 8 of the Federal Law No. 73-FZ an expert does research objectively, strictly on scientific and practical basis within the limit of relevant 
specialty, from all angles and completely. The expert's conclusion should be based on regulations that give possibility to check propriety and accuracy of conclusions on the base of generally accepted scientific and practical information.

It makes it possible for participants of judicial disputes to understand this demand relating to forensic-technical examination as the duty of an expert is to meet the requirements of the Federal Law No.102-FZ of the Russian Federation "On providing measurements' unity" dated June 26th, 2008, with regard to metrological attestation of the applied methods. In accordance with Paragraph 25 of the Federal Law No. 73FZ in expert's conclusion there must be section that reflects "content and results of investigations together with an indication of the methods applied".

Since 2015, the Forensic Examination Technical Committee No. 134 of Rosstandard of Russia has been developing regulations for types of examinations that control correspondence to the requirements of the Federal Law determined above. A variety of regulations have already been approved, for example for Trace Examination that allowed to prove accuracy of our Trace Examination methods and dispose wrong conclusions of the Swiss experts about opening of containers for keeping sportsmen's doping tests in the International Arbitrage in Lausanne. As a result, 28 of our Olympic Sochi Games winners were completely rehabilitated.

We suppose that because of the importance and above average demand for examination of inscriptions on the documents in civil, criminal, administrative and arbitral processes creating legitimised natural collections of standard samples and their digitalisation and also their legislative preservation in technical regulations is one of the priority tasks of forensic expertise of documents in order to provide evidential significance of its results.

It seems that these databases as opposed to, for example, databases of fake money tickets and documents of state circulation can be freely spread among state and nonstate expert agencies and also at the international level in forensic-expert agencies that are a part of European Network of Forensic Science Institutes (ENFSI).

Another serious problem is the fact that actual Russian laws and regulations do not contain clear definition of the status of an expert of non-state expert agency.

A forensic expert who is a dual competence specialist along with the knowledge in basic science (for example in economics, philology, natural science) and forensic expertology must have deep legal knowledge, be a master in modern expert technologies, certified and approved methods of expert research.

Training of a forensic expert is not a mechanic combination of two educations judicial and another one - but complex integrative education that allows a student to 
get necessary professional competencies while two educations separately do not allow to do it and form an expert mind. Competencies are formed only after a few years of expert practice. That is why even two high educations are not enough. The legislator points out that a post of an expert in state forensic-expert agencies can be taken by the citizen of the Russian Federation who has higher education and got additional professional education in a specific expert specialisation in a manner set by laws and regulations of the relevant federal authorities of executive power (Paragraph 13 of the Federal Law No.73-FZ). It is obvious that there are qualifying requirements for nonstate experts about their education and training.

At the present time, there are several forms of training forensic experts.

The first one is the traditional form of obtaining a degree and additional professional education in specific expert specialisation defined as type of forensic expertise established by departmental classifiers, that are contained in relevant orders, in short form includes studying basics of criminalistics and forensic expertology; studying forensic-expert technologies in this expert specialisation, gaining expert competencies by internships in forensic-technical agencies; preparation of trial examination and graduate qualification work; getting a certificate about additional education in expert specialisation; attestation (certification) for the right to perform forensic examination of this type.

The integrated nature of all types of forensic examination allows to develop a universal approach to training forensic experts of different specialisations in terms of tertiary education. Training of forensic experts as specialisation of lawyers started at Higher Investigations School of the Ministry of Internal Affairs of the USSR in Volgograd in 1974.

In 1999 the State Educational Standard of Higher Education of the First Generation was introduced with the specialisation in Forensic Examination No. 35060 with qualification of "forensic expert". Moreover, training of forensic experts that previously had only been done in institutions of higher education of the Ministry of Internal Affairs of Russia and only training forensic experts, started in civil institutions of higher education of the Department of Education and Social Development of Russia. That is why since 2003 the name of qualification has been changed into "forensic expert" by the decision of the Department of Education and Social Development.

In 2004 the Federal State Educational Standard of Higher Education of the Second Generation was introduced in the specialisation 030502.65 - "forensic expertise" with the qualification "forensic expert". In 2011 the Federal State Educational Standard of Higher Education of the Third Generation was introduced in the specialisation 
No. 031003 - "forensic expertise" with the qualification "forensic expert". New Federal Educational Standard of Higher Education " $3+$ " in specialisation "Forensic Expertise", No. 40.05 .03 with the qualification "forensic expert" has been in force since December 2016.

Grouping forensic examinations in classes is used in creating educational programmes of specialisations as part of FES HE in specialisation 40.05.03 "Forensic Expertise" and also as part of organisation of laboratories in forensic-expert agencies.

Content of modern forensic-expert education in specialisation "Forensic Expertise" 40.05.03 " $3+$ " includes:

- Big complex of legal knowledge according to the programmes of training bachelors of legal studies;

- Knowledge from major subjects depending on expert specialisation;

- General expert knowledge;

- Special knowledge in types of expertise;

- Professional skills and competences as a result of laboratory works, series of training and controlling expertise and the internship;

- Graduation work on specific type of expertise.

The "Forensic Expertise" 40.05.03 "3+" includes 5 specialisations that cover classes and types of judicial expertise that are most spread in judicial proceedings: traditional, criminalistic, engineer-technical, expertise of substances, materials and products, economical and speech studies. It should be noted that in this case specialisation is major in training in some types of judicial expertise.

According to the standard forensic-technical examination is studied by all students apart from specialisation, but selection of major subjects of significantly differs for different specialisations. However, in all departmental classifiers forensictechnical examination refers to criminalistic expert examination. The programme of forensic examination specialisation includes general subject of scientific methods of forensic-expert examination where students learn most general information about chromatography, spectroscopy, methods of X-ray examination and others. Of course graduating students of this specialisation cannot get a certificate for the right to perform the examination of materials of documents and time of their creation. Additional education cannot fill in the gap in the field of natural science at the level that student can use complicated analytical equipment not automatically but understanding the essence of processes, and use methods skilfully. That is why we have expert mistakes and failures, unwillingness to learn to use new equipment. 
At the same time analytical chemistry, physical-chemical methods of analysis and others are major subjects for specialisation "Forensic Examination of Substances, Physical-Chemical Methods of Analysis and Products". However, examination of materials of documents and tools used for writing are not included in a variety of subjects for which certificates for the right to perform forensic examination are given.

We suppose that it is necessary to make amendments to departmental classifiers and classify the examination of materials of the documents and determining time period when they were created as examination of substances, physical-chemical methods of analysis and products.

As certification of non-state experts is still voluntary, for graduates of expert colleges (there are more than 30 such colleges in Russia already and part of them are members of Association of "Forensic Examination" that accredits colleges) the main document that verifies qualification of a non-state expert is a supplement to the diploma of higher education.

Unfortunately, without higher expert education non-state experts (majority of them still do not have it) have serious problems with the quality of additional education. Such education is provided most properly by the Board of Forensic Experts named after U.G. Korukhov that was established in order to implement unified state policy in the field of forensic expertise in 2008 by the main state forensic-expert organisations of Russia: Russian Federal Centre for Forensic Examination at the Ministry of Justice of Russia and Russian Centre for Forensic Examination at the Ministry of Healthcare of Russia. The Board integrates on professional basis organisations and agencies that work in the field of forensic examination and forensic-expert studies and also individual forensic experts, provides training and retraining and gives certificates for the right to perform examinations.

Nevertheless, there are no legal regulations in this field and there appeared a lot of structures that also give certificates, often even without any education if you pay for them. Such certificates can be given also to a person who has no qualification at all. In practice, it often happens that a person who has a certificate in any expert specialty got their basic education in quite a different field. Courts as a rule do not check the expert's qualification and are satisfied with a relevant certificate or just a diploma of any higher education that the expert has.

Of course, qualification of an expert must be verified by relevant documents but in judicial act it is often hidden which education the expert has so we again return to the problem described above. For example, an expert has higher education in economics 
but he takes up documents' examination because he or she has a certificate for the right to perform such examinations. Moreover, the procedure of giving such certificates is not regulated by law and it results in of "pseudo experts" who do not have any scientific basis in their conclusions.

For example, Butyrsky court of Moscow had the criminal case No. XXX235 in which computer-technical examination was required. The examination was appointed to be performed in non-state forensic-expert agency. Its director had higher education in economics and he created board of experts at his agency. It consisted of himself (President) and two of his sons (with degrees in Law and Biology), passed the qualifying exam there and signed a certificate for the right to perform forensic examination of documents.

When writer of these words appeared before the court in accordance with p. 271, p. 4 she pointed out to the circumstances described above and also to poor observance of methods of forensic computer-technical examination by an expert that caused improper conclusions. As a result, the examination was acknowledged null and void. Repeated examination led to just the opposite conclusions and court acquitted the suspect.

In some cases, courts are seriously considering qualification of an expert. Thus, for example in case No. A19-18951/09 the decision of the court of original jurisdiction was cancelled by the judgment of the Fourth Arbitration Court of Appeal from January $2^{\text {nd }}, 2011$, and question about appointing expertise was remanded for retrial. The Court of Appeal pointed out that the court of original jurisdiction appointed a non-state expert agency for performing the examination without specifying which expert should perform the examination, without clarifying professional information, qualification, length of work and experience of experts, presence of special knowledge in questions of designing construction, including designing construction of basins of oil transfer pumping stations. The cassation instance concurred in the conclusion with the Court of Appeal. In decision of FAC of North-West District dated October 24 $4^{\text {th }}, 2017$ in the case No. A56-91576/2016 the court also pointed out that the conclusion of the customs expert also got proper legal evaluation when considering the case. In particular, the court of original jurisdiction outlined that it cannot rely upon that conclusion because materials of the case do not have documents that verify qualification and enforcement powers of the expert for performing the examination and expert's conclusions are contradictive and not full.

Unfortunately, inconclusive competence or lack of it is an argument for challenging of the expert in the Russian Federation Code of Criminal Procedure (p. 3, p. 2, p. 70 of 
RFCCP RF). In other codified laws, there is no regulation about challenging an expert in case when his incompetence was revealed.

Some scientists-processualists, for examples authors of the note on the APC RF 2007, suppose that it is reasonable because a person who does not have special knowledge even if he or she is called an expert will be hardly able to give a qualified conclusion to the arbitration court. Moreover, people who participate in the case have a right to feedback on doubts in choosing a particular expert and expert's conclusion has to be evaluated together with other evidence and will not be accepted by the court in case of lack of substantiation. In cases when the expert's conclusion causes doubts in the area of methods applied and their competence, the law provides for additional or repeated examination. Authors of the mentioned note innocently bank on the fact that an expert can give up on providing a conclusion if he or she does not have necessary knowledge (Note on Civil Procedure Code..., 2007).

Authors of the notes on the APC RF and the CCP RF adhere to the opposite notion and we fully share it (Note on Arbitration Procedure Code..., 2007). The question about how qualified the expert's conclusion is, in other words the question about the expert's conclusion evaluation is very complicated because judges do not have specific knowledge and it is hard for them to understand expert technologies considering the fact that in modern conditions of scientific-technical revolution expert methods have become more and more complicated.

Judges evaluate the expert's conclusion generally on formal grounds. What about expert's refusal to perform the examination they can be faithfully mistaken and not see the mistakes. That is why it appears that if the expert's incompetence is revealed at the early stage when the examination is appointed there must be a possibility to challenge them (Rossinskaya, 2018: 85).

\section{Conclusion}

Summarising the above we should select the key ways of solving technical and legal problems that experts working in the field of determining the date of inscriptions made on documents face.

The technical aspect of solving the problem is the fact that only a complex study using different methods of chemical-physical analysis is potentially able to give a clear result in most cases. In connection with that when performing an examination it is desirable that the chromatographic method is not used as the only instrument of expert's analysis but it must take place as a necessary stage of the examination. Thus, 
choosing a suitable method of examination is in many respects the key factor that allows to get the expert's conclusion that will be accepted by court and will not give rise to appointing repeated examination. The first suitable method for this purpose that was invented is the Raman spectroscopy method.

Examples of such approach can be conclusions in arbitration cases where the methods of the Ministry of Justice (Borisova, Trosman, Chertkova, 2008; Tuhkanen, Maslennikov, Tovkach, 2011) and the Raman spectroscopy method (Gorshkova et al., 2016; Grechukha et al., 2017) were applied simultaneously.

Implementation of such methods demands testing and will not be full in lack of universal digital databases that should gradually become an essential part of expert methods as natural collections and replace them.

The introduction of the new approach will be impossible without legal regulation of the status of such databases, rules for their creation and storage in actual condition and new technical regulations should be approved for that.

Certainly, the Federal Law No.73-FZ "About state forensic-expert activity in the Russian Federation" has become obsolete in many respects and it demands serious improvements. Predominantly it is related to defining the legal and organisational status of a non-state forensic-expert, their directors, clear requirements for forensic experts' qualification, their competence that must be checked regularly by attestation or certification.

Implementation of laws and regulations will demand developing more detailed requirements to experts in specific field laws and regulations.

\section{References}

Aginsky, V.N. (1993). "Some new ideas for dating ballpoint inks - a feasibility study”. In J Forensic Sci., 38, 1134-50.

Aginsky, V.N. (1996). "Dating and characterizing writing, stamp pad and jet printer inks by gas chromatography/mass spectrometry”. In Int J Forensic Doc Examiners, 2, 103-15.

Barinova, O.A. (2015). Criminalistic examination of requisites of documents that were produced with modern writing materials: theoretical and practical aspects. Dissertation on for degree of Candidate of Juridical Sciences. Volgograd, Ministry of Internal Affairs of Russian Federation Volgogranskaya Academy, $290 \mathrm{p}$.

Beeva, T.A. (2003). Criminalistic examination of faked foreign passports. Authorized summary. Candidate of Juridical Sciences. Volgograd. 
Borisova, E.A., Trosman, E.A., Chertkova, T.B. (2008). Modern possibilities of examination of prescription of documents. Problems of examination of inscription of particulars of documents. Materials of Russian national interdepartmental researchto-practice conference. Saratov, October 2008.

Bügler, J.H., Buchner, H., Dallmayer, A. (2005). Characterization of ballpoint pen inks by thermal desorption and gas chromatography-mass spectrometry". In J Forensic Sci, 50, 1209-14.

Bügler, J.H., Buchner, H. and Dallmayer, A. (2008). Age determination of ballpoint pen ink by thermal desorption and gas chromatography-mass spectrometry". In J. Forensic Sci., 4 (53), 982-988.

Causin, V. et al. (2008). The discrimination potential of ultraviolet-visible spectrophotometry, thin layer chromatography, and Fourier transform infrared spectroscopy for the forensic analysis of black and blue ballpoint inks. In J. Forensic Sci., 6 (53), 1468-1473.

Chaplin, T.D., Clark, R.J.H. (2006). Raman microscopy techniques for the characterization of pigments. In Infocus magazine, 3, 86-98.

Cherenkov, A.M. (1992). Automatized factographic informational-searching system “SCRIPT-II”. Moscow, EKC MIA RF, 34 p.

Cruces-Blanco, C., Gámiz-Gracia, L. and García-Campaña, A.M. (2007). Applications of capillary electrophoresis in forensic analytical chemistry. In $\operatorname{Tr} A C-$ Trends Anal. Chem., 3 (26), 215-226.

Dirwono, W., Park, J.S., Agustin-Camacho, M.R., Kim, J., Park, H. M., Lee, Y., Lee, K.B. (2010). Application of micro-attenuated total reflectance FTIR spectroscopy in the forensic study of questioned documents involving red seal inks, Forensic Sci. Int., 199, 6-8.

Gaudreau, M., Brazeau, L. (2002). Ink dating using a solvent loss ratio method. Proceedings of the 60th Annual Conference of the American Society of Questioned Document Examiners, August 14-18. San Diego (CA). Long Beach (CA): American Society of Questioned Document Examiners.

Geiman, I., Leona, M., Lombardi, J.R. (2009). Application of Raman spectroscopy and surface-enhanced Raman scattering to the analysis of synthetic dyes found in ballpoint pen inks. In J. Forensic Science, 54, 947-952.

Gorshkova, K.O., Tumkin, I.I., Myund, L.A., Tverianovich, A.S., Mereshchenko, A.S., Panov, M.S., Kochemirovsky, V.A. (2016). The investigation of dye aging dynamics in writing inks using Raman spectroscopy. In Dyes and Pigments 131, 239-245. 
Grechukha, N.M., Gorshkova, K.O., Panov, M.S., Tumkin, I.I., Kirillova, E.O., Lukianov, V.V., Kirillova, N.P., Kochemirovsky, V.A. (2017). Analysis of the Aging Processes of Writing Ink: Raman Spectroscopy versus Gas Chromatography Aspects. In Applied Sciences 7(10).

Kalantzis, N.D. (2008.) Paper interference in ink Raman spectra at $685 \mathrm{~nm}$ : A preliminary report, presented at the XIII Scientific Symposium of Handwriting Expertise, Wroclaw, Poland.

Kher, A., Mulholland, M., Green, E., Reedy, B. (2006). Forensic classification of ballpoint pen inks using high performance liquid chromatography and infrared spectroscopy with principal components analysis and linear discriminant analysis. In Vibrational Spectroscopy, 40, 270-277.

Kochemirovskiy, V.A., Kirillova, E.O., Gorshkova, K.O., Borisov, E.N. (2015). Detection of document artificial aging evidence: research of optical brighteners fuorescence signals on paper surface: News of science: Proceedings of materials the international scientific conference. Czech Republic, Karlovy Vary - Russia, Moscow, 25-28.

Lociciro, S., Dujourdy, L., Mazzella, W., Margot, P., Lock, E. (2004). Dynamic of the ageing of ballpoint pen inks: quantification of phenoxyethanol by GC-MS. In Sci Justice, 44(3), 165-71.

Lombardi, J.R., Leona, M., Vo-Dinh, T., Antoci, P. (2006). Development of advanced Raman spectroscopy methods and databases for the evaluation of trace evidence and the examination of questioned documents, vol. 146.

Mazzella, W. D. and Buzzini, P. (2005). Raman spectroscopy of blue gel pen inks. In Forensic Sci. Int., 2-3 (152), 241-247.

Mitrichev, L.S., Kolmakov, A.I., Rossinskaya, E.R. et al. (1992). Diagnostics of reasons of break-downs of steel guides, taken away from places of fire. Methodical recommendations. Moscow, EKC MIA RF, 89 p.

Note on Civil Procedure Code of Russian Federation (edited by V.M. Zhuikov and M.K. Treushnikov) (2007). Moscow, SPS ConsultantPlus.

Note on Arbitration Procedure Code of Russian Federation (paragraph-byparagraph) (edited by M. S. Shakaryan); (author of p. 3 "Challenges” - A. T. Bonner), SPS ConsultantPlus, 54-55.

Rossinskaya, E.R. (2002). Note on Federal Law "On state forensic-expert activity in theRussian Federation”, Moscow, Law; Urait-Izdat, 384 p.

Pakhomov, A.V. (1998). Scientific basics, organization and using natural collections in detection and investigation of crime. Author's summary of dissertation on for degree of Candidate of Juridical Sciences, Moscow. 
Reisner, L.A., Cao, A., Pandya, A.K. (2011). "An integrated software system for processing, analyzing, and classifying Raman spectra". In Chemometrics and Intelligent Laboratory Systems. 105, 83-90.

Rossinskaya, E.R., Galyashina, E.I. (2009). Non-state expert agencies, legal status and their organizational forms. In Legalness, 2, 28-32.

Rossinskaya, E.R., Galyashina, E.I., Zinin, A.M. (2016). Theory of judicial expertise (judicial expertology): study book, Moscow, Norma INFRA-M, 368 p.

Rossinskaya, E.R. (2018). Judicial expertise in civil, arbitration, administrative and criminal process: monograph (4 ${ }^{\text {th }}$ edition), Moscow, Norma INFRA-M, 576 p.

Samanidou, V.F., Nikolaidou, K.I., and Papadoyannis, I.N. (2004). Development and Validation of a Gradient-HPLC-PDAD Method for the Identification of Ballpoint Pen Ink Components: Study of Their Decomposition on Aging for Forensic Science Applications. In J. Liq. Chromatogr. Relat. Technol., 2 (27), 215-235.

Shevchenko, T.N., Temerdashev, Z.A., Kiseleva, N.V. (2012). Identification and determination of aromatic dyes in ballpoint inks by HPLC with spectrophotometric and mass spectrometric detection. In Analitika i control [Analytics and control], 3 (16).

Shvedova, N.N. (1999). Applying computer technologies in technical-criminalistic documents' examination. Authorized summary. Candidate of Juridical Sciences. Volgograd.

Silva, C.S., Borba, F. de S.L, Pimentel, M.F., Pontes, M.J.C., Honorato, R.S. and Pasquini, C. (2013). Classification of blue pen ink using infrared spectroscopy and linear discriminant analysis. In Microchem. J., (109), 122-127.

Sitnikov, V.B., Venevtcev, A.N. (2009). To the question of establishing time limits of production of marks of inks of ball-point pens. In Voronezhsky lawyer, 12.

Smelkov, G.I. (2009). Fireworthiness of wiring, Moscow, Kabel.

Sretensev, D.N. (2009). Legal, organizational and methodic aspects of informational-analytical support of judicial-expert activity. Authorized summary. Candidate of Juridical Sciences. Moscow.

Tebbet, I., Chen, C., Fitgerald, M., Olsen L., (1992). The use of HPLC with multiwavelength detection for the differentiate of non-ball pen inks. In Journal of Forensic Science.

Technical expertise of documents (2004). In book "Capabilities of judicial expertise production in state judicial-expert agencies of Justice ministry of Russia”. Scientific publication. Moscow.

Tuhkanen, O.V., Maslennikov, V.G., Tovkach, E.G. (2011). Examination of inscriptions made with gel inks for establishing time limits of production of them. 
In collection Development of new types and styles of judicial expertise: materials of Russiannationalworkshop (compiled by T.M. Zhakova, O.V. Tukhanen, M.A. Voznyuk, S.S. Shipshin). Rostov-on-Don.

Weyermann, C., Kirsch, D., Costa Vera, C., Spengler, B. (2007). A GC/MS study of the drying of ball point pen ink on paper. In J. Forensic Sci., 168 (2-3), 119-127.

Zlotnick, J.A, Smith, F.P. (1999). Chromatographic and electrophoretic approaches in ink analysis. In J. Chromatogr. B, 733, 265-272.

\title{
Задачи судебно-технической экспертизы документов для определения давности их изготовления
}

\author{
Е.Р. Россинская ${ }^{a}$, К.О. Горшкова ${ }^{\sigma}$, Н.П. Кириллова ${ }^{\sigma}$, \\ Н.Г. Стойко \\ В.А. Кочемировский \\ ${ }^{a}$ Московский государственный юридический университет \\ им. О.Е. Кутафина \\ Россия, 125993, Москва, ул. Садовая-Кудринская, 9 \\ ${ }^{6}$ Санкт-Петербургский государственный университет \\ Россия, 199034, Санкт-Петербург, \\ Университетская набережная, 7/9 \\ ${ }^{8}$ Межрегиональная экономико-правовая коллегия \\ Россия, 196105, Санкт-Петербург, ул. Благодатная, 69, 1Д
}

В статье рассматриваются проблемы судебно-технической экспертизы по определению рукописных подписей (надписей). Описаны основные методики проведения такой экспертизы, а также проблемы, с которыми сталкиваются специиалисты. Подняты вопросы квалификачии экспертов и даны рекомендации по выбору экспертного учреждения и эксперта. В статье приведены ссылки на научные материаль в российских и зарубежных изданиях, а также примеры действующего законодательства и судебной практики арбитражных судов Российской Федерачии.

Ключевые слова: экспертиза, фальсификачия документов, газовая хроматография, рамановская спектроскопия, датировка документа, единство измерений, квалификациия специалиста.

Исследование выполнено при финансовой поддержке РФФИ в рамках научного проекта № 18-29-16003|18.

Научная специальность: 12.00.00 - юридчческие науки. 